\title{
High-Voltage Electric Field-Assisted Thawing of Frozen Tofu: Effect of Process Parameters and Electrode Configuration
}

\author{
Changjiang Ding ${ }^{D}$, Jiabao Ni, Zhiqing Song, Zhiwei Gao, Shilong Deng, Jing Xu, \\ Guoqing Wang, and Yu Bai
}

College of Science, Inner Mongolia University of Technology, Hohhot, China

Correspondence should be addressed to Changjiang Ding; ding9713@163.com

Received 25 March 2018; Revised 31 May 2018; Accepted 28 June 2018; Published 16 July 2018

Academic Editor: Francesco Donsi

Copyright (c) 2018 Changjiang Ding et al. This is an open access article distributed under the Creative Commons Attribution License, which permits unrestricted use, distribution, and reproduction in any medium, provided the original work is properly cited.

\begin{abstract}
Applying high-voltage electric field (HVEF) to some food materials has been shown to increase the thawing rate. To investigate the effect of process parameters and electrode configuration in high-voltage electric field system, we took the frozen tofu as the research object and investigated the influence of the different voltages, electrode configuration, and electrode distances on thawing process. The thawing time, center temperatures, and loss rate of samples were measured. The results showed that the thawing time of frozen tofu decreases with the increase of voltage and the thawing time has a great relevance with configuration and distance of electrodes. The electric parameters have a major effect on thawing loss and thawing time when center temperatures of frozen tofu are from $-2^{\circ} \mathrm{C}$ to $0^{\circ} \mathrm{C}$. This work provides clues and experimental basis for the further application of high-voltage electric field thawing technology.
\end{abstract}

\section{Introduction}

Thawing of frozen materials is an important component of food product processing. Many technologies are widely used in food thawing industry, such as cold and warm water thawing, still air thawing, refrigerator thawing, and so on. However, all have their own shortcomings, which greatly affects the products' subsequent production and market competitiveness, including higher color deterioration and weight loss, longer thawing time, and decreased nutritional value of the thawed products. Therefore, it is significant to explore the new thawing technology.

High-voltage electric field (HVEF) thawing is an important nonthermal food processing method that has received considerable attention lately [1], and it is predominantly used to thaw food products in academia, including pork [2, 3], tuna fish [4-7], chicken [8], rabbit meat [9], shrimps [10], common carp [11], tofu [12], and apple tissue [13]. Compared to traditional thawing methods, high-voltage electric field thawing has many advantages $[3,6,10]$ such as reduced thawing time, food quality preservation, microbial growth inhibition, reduced energy consumption, and so on. The thawing can be carried out using either AC or DC high voltages. Multipoint and plate electrode systems are efficient in accelerating thawing of freeze materials [10]. When the thawing temperature was set at $-3^{\circ} \mathrm{C}$, the thawing time of frozen chicken under high-voltage electric field was $2 / 3$ the time taken for thawing meat [14]. The HVEF treatment significantly shortened the thawing time of frozen pork tenderloin meat, and thawing time was reduced to $2 / 3$ that of the control and reduced the total microbial counts in thawed frozen meat by 0.5-1 log CFU/g [2]. Mousakhani-Ganjeh et al. reported that the high-voltage electric field could increase susceptibility of tuna fish to lipid oxidation due to ozone generation [6]. In previous studies, we studied the thawing characteristic of frozen tofu from the thawing rate, center temperatures, thawing loss, specific energy consumption, and mathematical models under AC electric field at different voltages and found that the thawing rate of frozen tofu was notably greater in the high-voltage electric field system when compared to control [12]. Both linear and quadratic models were the best mathematical models [12]. 


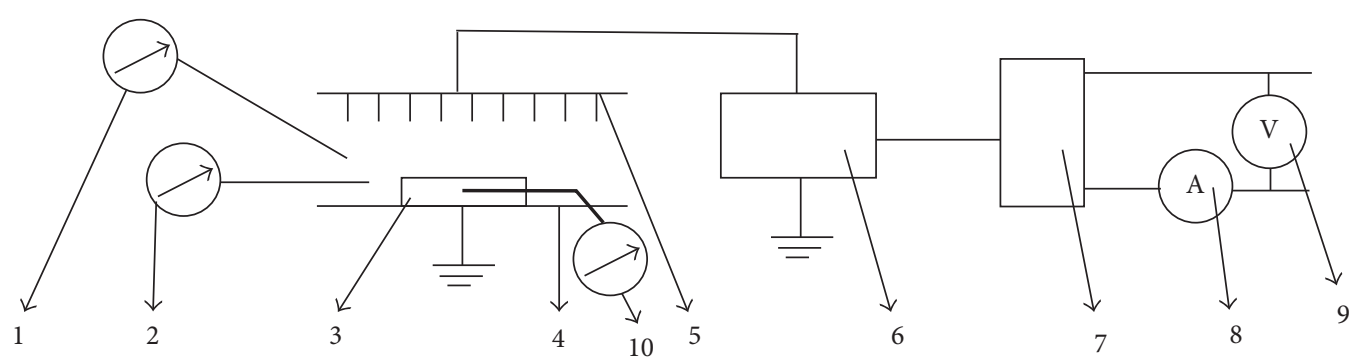

Figure 1: Schematic diagram of HVEF thawing. 1: thermometer; 2: hygrometer; 3: frozen tofu; 4: grounded plate electrode; 5: needle electrodes; 6: high-voltage power source; 7: voltage regulator; 8: amperometer; 9: voltmeter; 10: temperature sensor.

Despite the detail with which these studies treat the problem, few studies have systematically and comprehensively reported on the effects of process parameters and electrode configuration under different high-voltage electric field thawing conditions.

To further investigate the effect of process parameters and electrode configuration for optimizing and improving the thawing efficiency in high-voltage electric field system, we studied the thawing characteristic of frozen tofu. To accomplish this, high-voltage electric field thawing characteristics and quality of frozen tofu were studied, including the thawing electric voltage, thawing time, center temperatures of samples, thawing loss, and the configuration of the electrodes under different thawing conditions.

\section{Materials and Methods}

2.1. Experimental Facility. The thawing experimental equipment is shown schematically in Figure $1[12,15]$. The HVEF thawing equipment consists of three parts: highvoltage power system, thawing system, and control system. The thawing system consists of a high-voltage electrode, the configuration of which is multiple sharp pointed needles or wires or metallic plate, and a fixed horizontal grounded metallic plate. The electrode gaps between the high-voltage electrodes and the grounded electrode can be adjusted. The high-voltage electrodes were connected to a high-voltage power system that can supply alternating current (AC) or direct current (DC) high voltage. The frequency of the AC electric field was $50 \mathrm{~Hz}$. The high-voltage power (YD(JZ)$1.5 / 50$, made in Wuhan, China) was connected to a voltage regulator (KZX-1.5 KVA, made in Wuhan, China) as control system, with an adjustable voltage ranging from 0 to $50 \mathrm{kV}$ for $\mathrm{AC}$ or 0 to $70 \mathrm{kV}$ for $\mathrm{DC}$ by a controller. The grounded electrode was an $80 \mathrm{~cm} \times 40 \mathrm{~cm}$ rectangular stainless steel plate. The ambient temperature and relative humidity in thawing process were both measured. The voltage and current of HVEF system were measured by a voltmeter (made in Ningbo, China) and an amperometer (made in Ningbo, China), respectively. The metal needle which the length is $20 \mathrm{~mm}$ and diameter is $1 \mathrm{~mm}$ was evenly arranged on the needle plate electrode $(64 \mathrm{~cm} \times 40 \mathrm{~cm})$ by stainless steel wire. The distance between two needle electrodes was $40 \mathrm{~mm}$. The dimensions of high-voltage electrode with plate or wires were a $64 \mathrm{~cm} \times 40 \mathrm{~cm}$. The distance between two stainless steel wires was $40 \mathrm{~mm}$. All the samples were spread in a single layer on the grounded plate electrode at random. The center temperature of samples was measured by a temperature sensor.

2.2. Preparation and Treating of Tofu. The soft tofu was purchased from a local market near Inner Mongolia University of Technology, Hohhot, China. The fresh soft tofu was sliced into sheet about $3.5 \mathrm{~cm} \times 3.5 \mathrm{~cm} \times 3.5 \mathrm{~cm}$ using a knife and immediately frozen at $-18^{\circ} \mathrm{C}$ in a refrigerator (Hisense BCD-197T, made in Qingdao, China). The frozen samples were stored at $-18^{\circ} \mathrm{C}$ until use.

2.3. Measurement of Thawing Process and Thawing Time. We conducted three experimental conditions to further investigate the effect of process parameters and electrode configuration for optimizing and improving the thawing efficiency in high-voltage electric field system. The voltage, electrode configuration, and discharge gap were investigated, respectively.

Firstly, the frozen tofu was thawed under DC electric field with multiple needles-to-plate electrode at different voltages. The thawing voltage was $0 \mathrm{kV}$ (the control samples), $4 \mathrm{kV}$, $8 \mathrm{kV}, 12 \mathrm{kV}, 16 \mathrm{kV}, 20 \mathrm{kV}, 24 \mathrm{kV}$, or $28 \mathrm{kV}$, respectively. The corresponding discharge gap between the high-voltage electrodes and the grounded electrode was $100 \mathrm{~mm}$.

Secondly, the configuration of high-voltage electrodes was multiple needles-to-plate, multiple wires-to-plate, or multiple plate-to-plate electrodes, respectively, under AC electric field. The corresponding discharge gap between the high-voltage electrodes and the grounded electrode was $100 \mathrm{~mm}$. The corresponding voltage was $28 \mathrm{kV}$. The same thawing experiments were also investigated under DC electric field.

Lastly, the discharge gap between the emitting point and the grounded electrode each time at $8 \mathrm{~cm}, 9 \mathrm{~cm}, 10 \mathrm{~cm}$, $11 \mathrm{~cm}$, and $12 \mathrm{~cm}$ with multiple needles-to-plate electrode for AC electric field was changed, and the corresponding voltage was $20 \mathrm{kV}$. The sample thickness is lower than the discharge gap to make better use of the nonuniform electric field and the ion wind. And this would better reduce energy consumption during thawing.

The thawing temperature was $20 \pm 1^{\circ} \mathrm{C}$, the relative humidity was $30 \pm 5 \%$, and the ambient wind speed was $0 \mathrm{~m} / \mathrm{s}$. The center temperature of frozen tofu samples determined by a digital thermometer (made in China) and recorded at $5 \mathrm{~min}$ intervals during the thawing process. In 
this paper, "center temperature" refers to the temperature at the geometric center of frozen tofu samples, where heat takes longest to penetrate. Thawing was continued until the center temperature of the frozen tofu sample reached $10^{\circ} \mathrm{C}$. The time required to raise the center temperature from $-10^{\circ} \mathrm{C}$ to $10^{\circ} \mathrm{C}$ was determined as thawing time. Thawing experiments were independently performed three times in this study and the average was taken. In each thawing experiment, the sample is placed at the same position on the grounded electrode to keep the consistency of the experiment. It is found in other studies that both the center and surface temperatures of samples increased rapidly with the increase of applied voltages and have some similar characteristics [3]. So, we only measured the center temperature of frozen tofu to investigate the effect of process parameters and electrode configuration.

There are some electrochemical reactions during the thawing process, which may lead to electrode corrosion and metal release. When the electrode was designed, we use a protective paint on the surface to prevent electrode oxidation and corrosion. And there is no contact here between the electrode and the material during the thawing process. Then, the effect of electrochemical reaction on the thawing process is very small. We think that it can be ignored.

The thawing rate of material samples $(\mathrm{g} / \mathrm{s})$ was calculated using the following equation:

$$
\text { thawing rate }=\frac{\text { weight of frozen tofu }(\mathrm{g})}{\text { thawing time of frozen tofu }(\mathrm{s})} \text {. }
$$

2.4. Measurement of Evaporation Loss, Thawing Loss, and Drip Loss. Evaporation loss, thawing loss, and drip loss were measured by weighing the frozen and thawed material samples before and after the removal of surface water according to (2), (3), and (4), respectively:

$$
\begin{aligned}
& \text { evaporation loss }=\frac{\text { (weight of the frozen tofu })-(\text { weight of the thawed tofu before removing surface water })}{\text { weight of the frozen tofu }}, \\
& \text { thawing loss }=\frac{\text { (weight of the frozen tofu })-(\text { weight of the thawed tofu after surface water removal) }}{\text { weight of the frozen tofu }} \text {, }
\end{aligned}
$$

$$
\text { drip loss }=\text { thawing loss }- \text { evaporation loss. }
$$

Experiments were independently performed three times in this study and the average was taken.

2.5. Statistical Analysis. Single-factor analysis of variance was used to calculate the evaporation loss, thawing loss, and drip loss between the frozen tofu under alternating electric field and without electric field (control). The evaporation loss, thawing loss, and drip loss between different electric field were also calculated using single-factor analysis of variance. The differences in thawing loss are considered statistically significant when $p<0.05$.

\section{Results and Discussion}

3.1. Thawing Time and Thawing Rate Analysis. Figure 2(a) shows the effect of different voltages on the thawing time and thawing rate under DC electric field. The frozen tofu was thawed at $20^{\circ} \mathrm{C}$ with a fixed discharge gap of $10 \mathrm{~cm}$ under DC electric field. The thawing times at $0 \mathrm{kV}$ (the control), $4 \mathrm{kV}, 8 \mathrm{kV}, 12 \mathrm{kV}, 16 \mathrm{kV}, 20 \mathrm{kV}, 24 \mathrm{kV}$, and $28 \mathrm{kV}$ under DC electric field were $200 \mathrm{~min}, 155 \mathrm{~min}, 150 \mathrm{~min}$, $145 \mathrm{~min}, 140 \mathrm{~min}, 135 \mathrm{~min}, 130 \mathrm{~min}$, and $125 \mathrm{~min}$, respectively. In other words, the thawing times treated with the high-voltage electric field were significantly shortened than those of the control $(0 \mathrm{kV})$. With the increase of voltage, the thawing time decreased. The high-voltage electric field could obviously accelerate the thawing rate of tofu samples compared to that of the control, and increasing the voltage had a major effect on the enhancement of the thawing rate. These results agree with those studies which reported enhancement in thawing rate with increase of applied voltage $[3,4]$. At present, it is generally believed that the main reason of thawing rate accelerating is the generation of corona wind which was produced by the high-voltage electric field. The samples are put on a metal plate (cathode), while electrodes are mounted in some distance to the cathode and will form a corona when the electric circuit is closed [16]. Under the HVEF system, the corona wind produced impinges on the material and disturbs the liquid part of the thawing tofu, leading to thawing enhancement. The corona electrode with small curvature radius could form a nonuniform HVEF and realize a corona discharge in the gas-filled gap. The corona wind would be higher when the configuration of the electrodes is adopted in the form of needle-to-plate or wire-plate rather than the plate-to-plate form. Thus, the configuration of the electrodes would impact on the thawing rate of frozen food.

Figure 2(b) shows the effect of different configuration of the electrodes on the thawing time and thawing rate. The thawing times for the electrodes of plate-to-plate under DC 

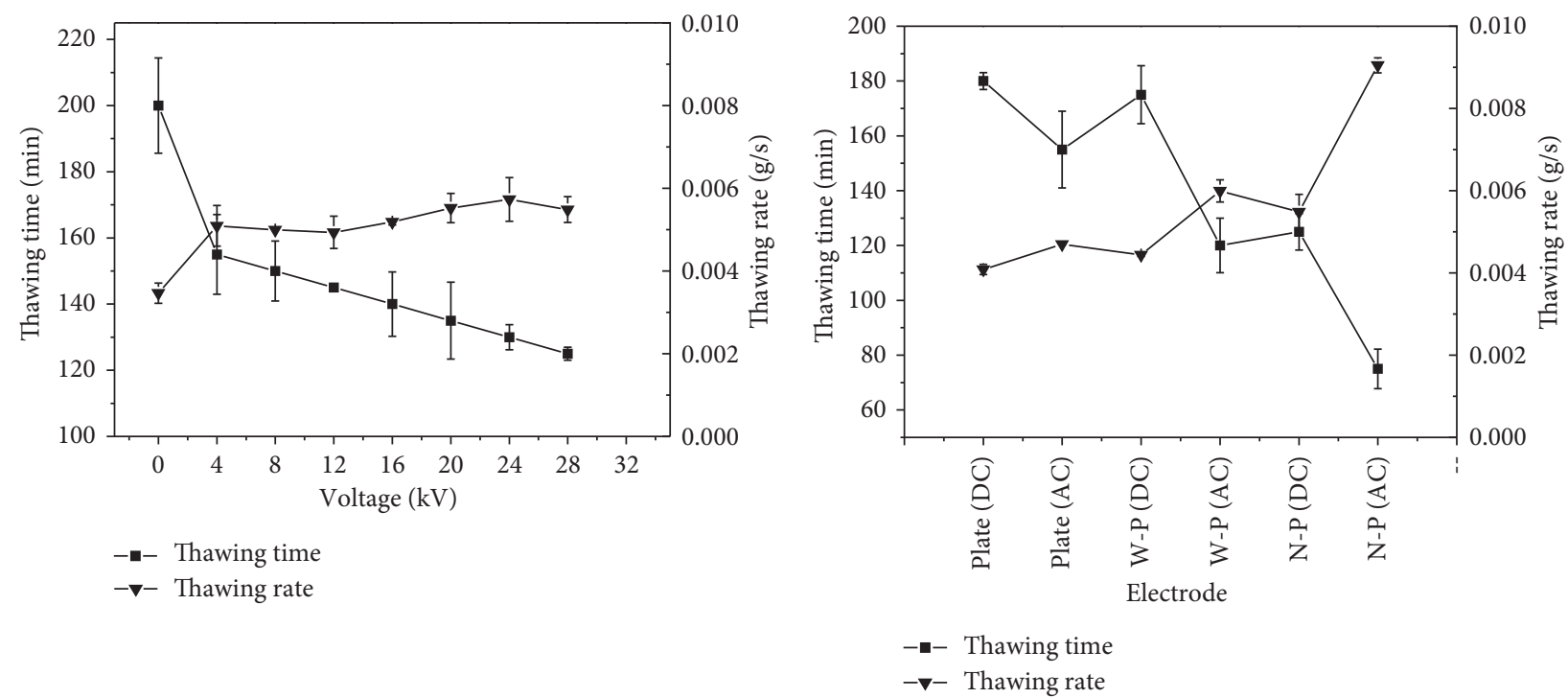

(a)

(b)

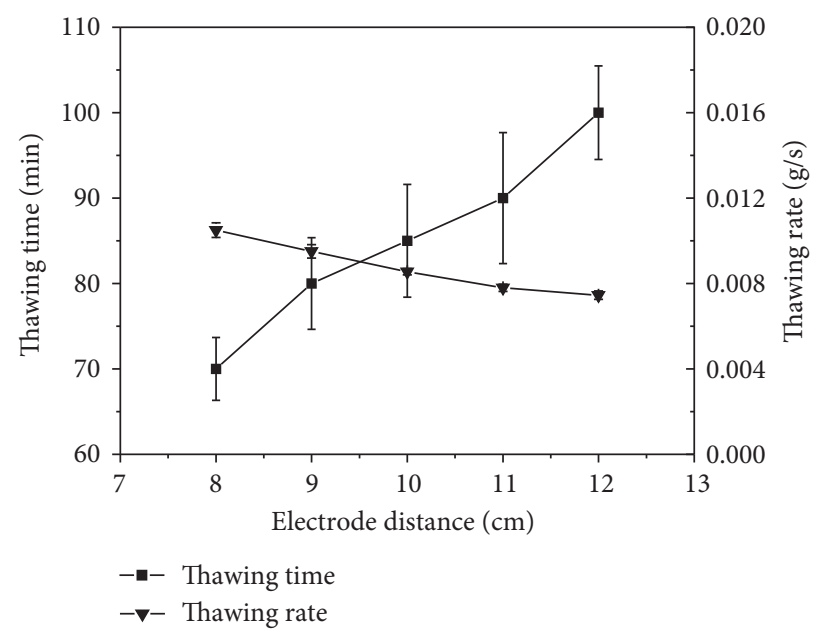

(c)

Figure 2: (a) Thawing time and thawing rate of frozen tofu in different voltages. The frozen tofu was thawed at $20^{\circ} \mathrm{C}$ with a fixed discharge gap of $100 \mathrm{~mm}$ under DC electric field. The thawing voltage was $0 \mathrm{kV}$ (the control samples), $4 \mathrm{kV}, 8 \mathrm{kV}, 12 \mathrm{kV}, 16 \mathrm{kV}, 20 \mathrm{kV}, 24 \mathrm{kV}$, or $28 \mathrm{kV}$, respectively.(b) Thawing time and thawing rate of frozen tofu in different electrodes. Plate (DC): the plate-to-plate electrodes under DC electric field, plate (AC): the plate-to-plate electrodes under AC electric field, W-P (DC): the wires-to-plate electrodes under DC electric field, $\mathrm{W}-\mathrm{P}(\mathrm{AC})$ : the wires-to-plate electrodes under AC electric field, N-P(DC): the needles-to-plate electrodes under DC electric field, and $\mathrm{N}-\mathrm{P}(\mathrm{AC})$ : the needles-to-plate electrodes under AC electric field. The corresponding discharge gap between the high-voltage electrodes and the grounded electrode was $100 \mathrm{~mm}$. The corresponding voltage was $28 \mathrm{kV}$ (c) Thawing time and thawing rate of frozen tofu in different electrode distances. The discharge gap was $8 \mathrm{~cm}, 9 \mathrm{~cm}, 10 \mathrm{~cm}, 11 \mathrm{~cm}$, and $12 \mathrm{~cm}$ with multiple needles-to-plate electrode for AC electric field, respectively. The corresponding voltage was $20 \mathrm{kV}$.

electric field, plate-to-plate under AC electric field, wires-toplate under DC electric field, wires-to-plate under AC electric field, needles-to-plate under DC electric field, and needles-to-plate under AC electric field were $180 \mathrm{~min}$, $155 \mathrm{~min}, 175 \mathrm{~min}, 120 \mathrm{~min}, 125 \mathrm{~min}$, and $75 \mathrm{~min}$, respectively. We can see that the thawing time under AC electric field was shortened significantly when compared to that under DC electric field. The thawing time for the electrodes of needles-to-plate under AC electric field was the shorter than that under the other experimental conditions. And the thawing time for the electrodes of plate-to-plate under DC electric field was the longer than that under the other experimental conditions. The thawing rate of tofu samples treated with AC electric field is higher than that treated with DC electric field. From Figure 2(b) shows that the thawing rate of frozen tofu under AC electric field is higher than that under DC electric field when they have the same voltage and electrodes. Therefore, another high-voltage electric field thawing mechanism is possible besides corona wind under the AC electric field. As water molecules are highly polar, they orient themselves in the direction of the electric field, which in-turn would lead to the conversion of 


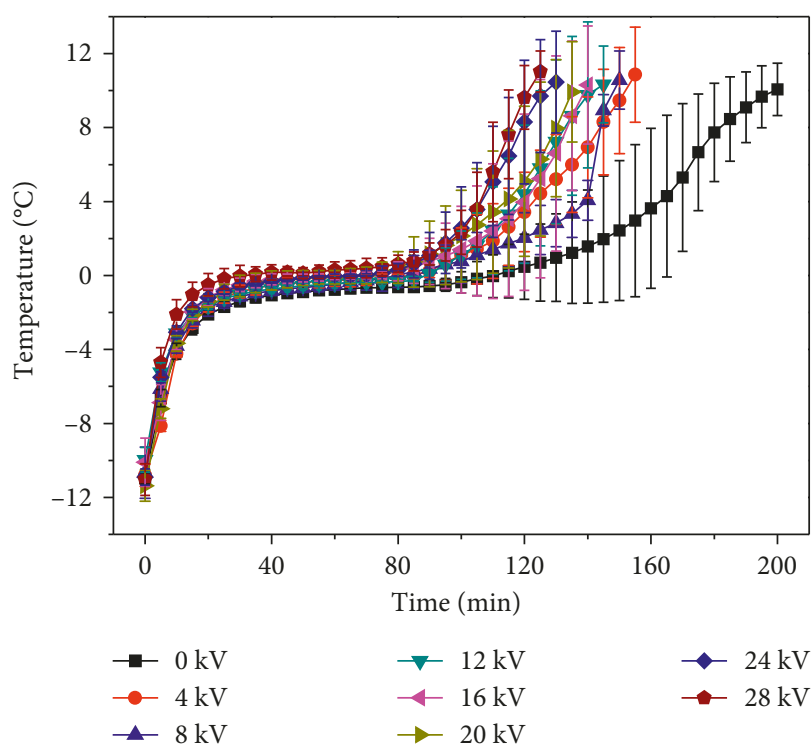

(a)

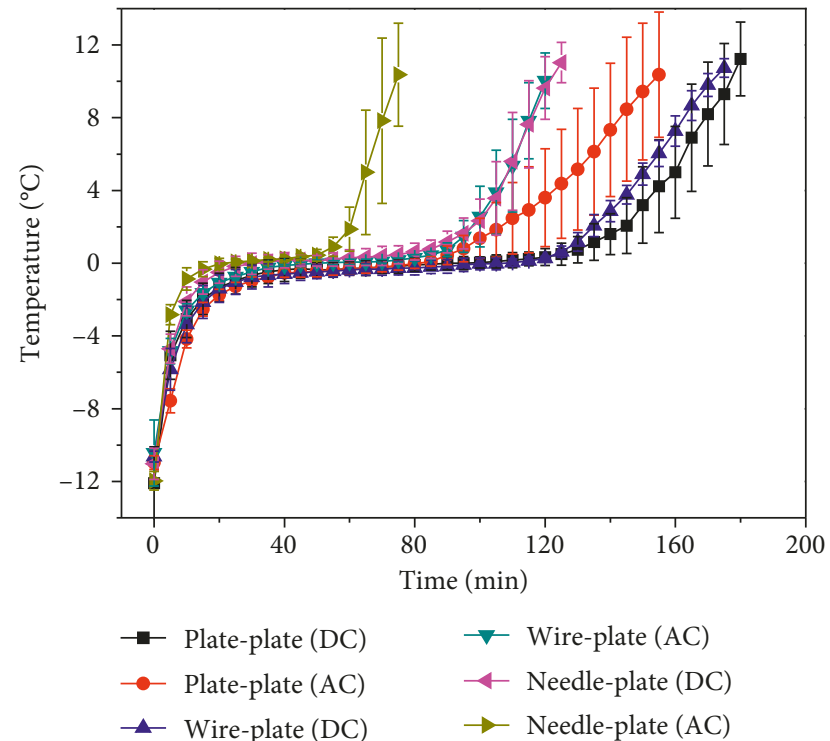

(b)

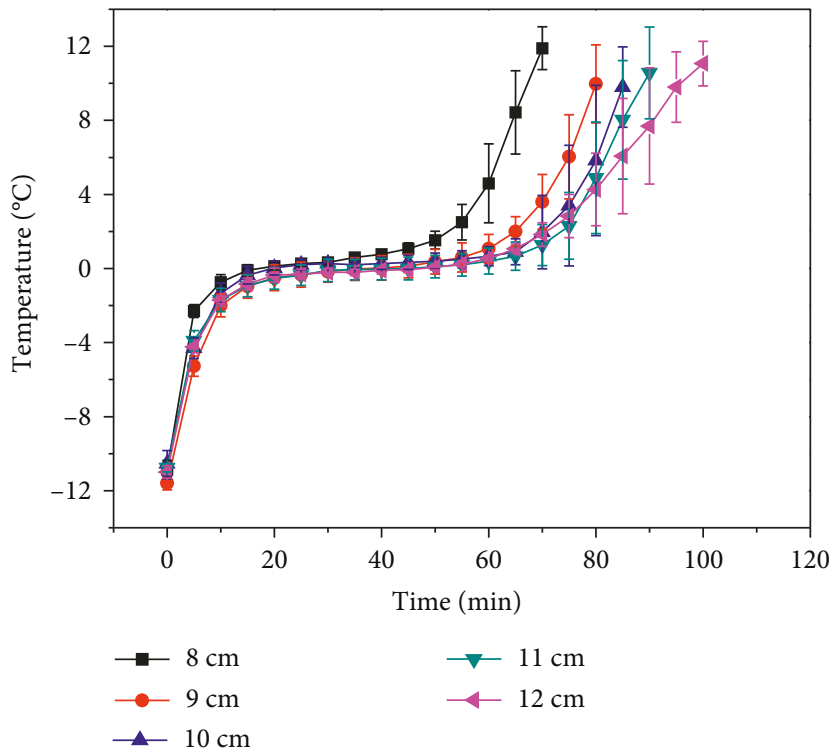

(c)

Figure 3: (a) Changes in temperature during thawing of frozen tofu in different voltages. The frozen tofu was thawed at $20^{\circ} \mathrm{C}$ with a fixed discharge gap of $100 \mathrm{~mm}$ under DC electric field. The thawing voltage was $0 \mathrm{kV}$ (the control samples), $4 \mathrm{kV}, 8 \mathrm{kV}, 12 \mathrm{kV}, 16 \mathrm{kV}, 20 \mathrm{kV}, 24 \mathrm{kV}$, or $28 \mathrm{kV}$, respectively. (b) Changes in temperature during thawing of frozen tofu in different electrodes. The corresponding discharge gap between the high-voltage electrodes and the grounded electrode was $100 \mathrm{~mm}$. The corresponding voltage was $28 \mathrm{kV}$. (c) Changes in temperature during thawing of frozen tofu in different electrode distances. The discharge gap was $8 \mathrm{~cm}, 9 \mathrm{~cm}, 10 \mathrm{~cm}, 11 \mathrm{~cm}$, and $12 \mathrm{~cm}$ with multiple needles-to-plate electrode for AC electric field, respectively. The corresponding voltage was $20 \mathrm{kV}$.

electrical energy into mechanical energy, thereby forcing water molecules out of the material [12]. Relevant study also showed that the high field intensity can reorient water molecules in ice and modify the crystal morphology, so that freezing is inhibited, leading to the acceleration of the thawing process [17].

Figure 2(c) that the effect of different discharge gaps on the thawing time and thawing rate. The thawing times for the discharge gaps of $8 \mathrm{~cm}, 9 \mathrm{~cm}, 10 \mathrm{~cm}, 11 \mathrm{~cm}$, and $12 \mathrm{~cm}$ were $70 \mathrm{~min}, 80 \mathrm{~min}, 85 \mathrm{~min}, 90 \mathrm{~min}$, and $100 \mathrm{~min}$, respectively. As discharge gap increased, the thawing time increased.
These results are similar with what has been found in other studies $[3,4]$. The electric field strength decreases with the increase of discharge gap. The magnitude of the electric wind velocity was proportional to the electric field strength. So, decreasing the discharge gap had a major effect on the enhancement of the thawing rate.

3.2. Center Temperatures Analysis. The center temperatures exposed to high-voltage electric field are shown in Figure 3. The results indicate that within the first $10 \mathrm{~min}$, the center 

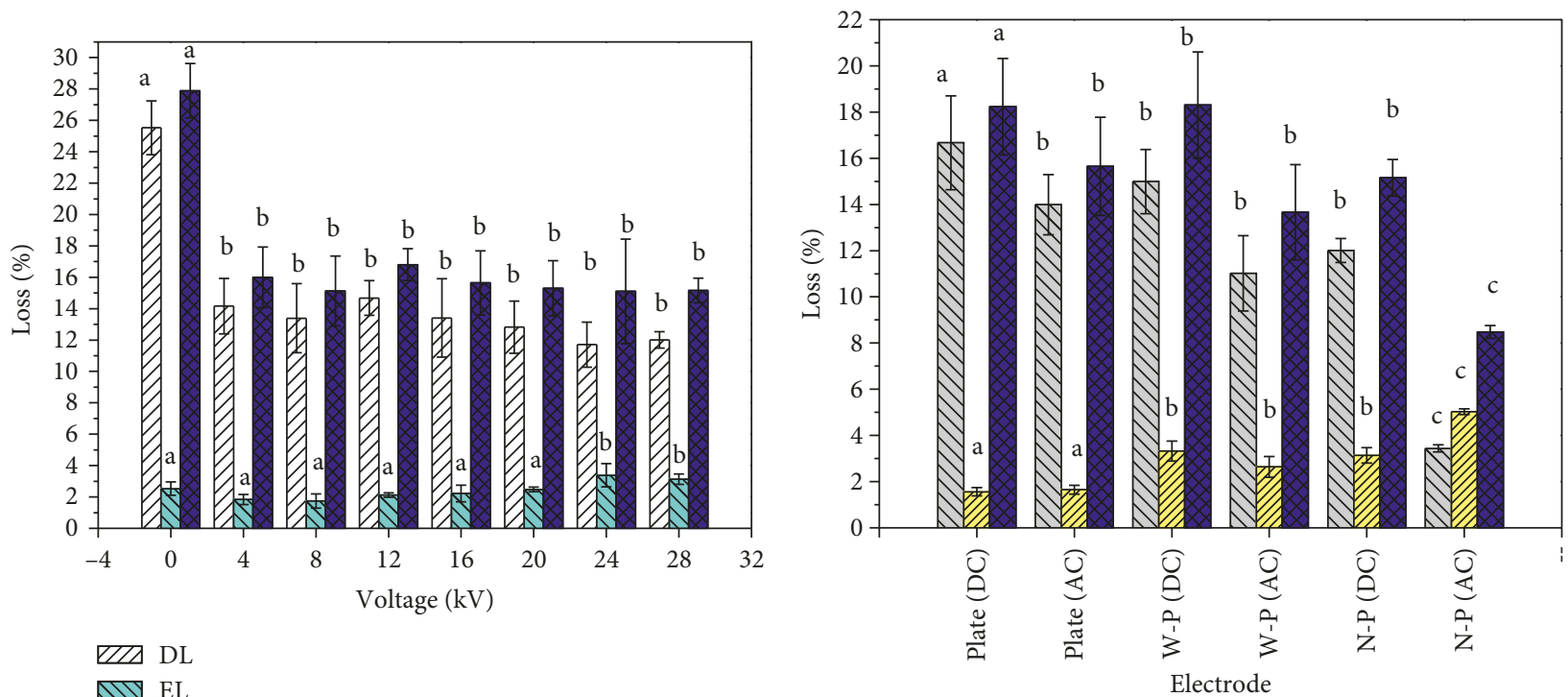

VIIJ DL

IIV EL

MII DL

VIII EL

$\mathrm{TL}$

(a)

(b)

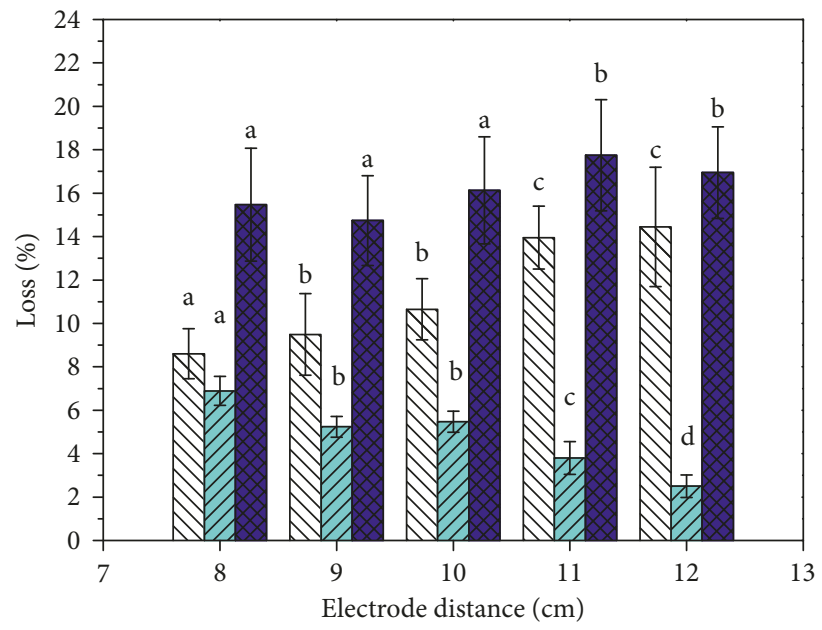

MIV DL

IIS EL

$\mathrm{TL}$

(c)

Figure 4: (a) The evaporation loss, thawing loss, and drip loss of tofu under different voltages. The frozen tofu was thawed at $20^{\circ} \mathrm{C}$ with a fixed discharge gap of $100 \mathrm{~mm}$ under DC electric field. The thawing voltage was $0 \mathrm{kV}$ (the control samples), $4 \mathrm{kV}, 8 \mathrm{kV}, 12 \mathrm{kV}, 16 \mathrm{kV}, 20 \mathrm{kV}$, $24 \mathrm{kV}$, or $28 \mathrm{kV}$, respectively. For each treatment, means with different lower case letters are significantly different $(p<0.05)$. (b) The evaporation loss, thawing loss, and drip loss of tofu under different electrodes. Plate (DC): the plate-to-plate electrodes under DC electric field, plate (AC): the plate-to-plate electrodes under AC electric field, W-P (DC): the wires-to-plate electrodes under DC electric field, W-P (AC): the wires-to-plate electrodes under AC electric field, N-P (DC): the needles-to-plate electrodes under DC electric field, and N-P (AC): the needles-to-plate electrodes under AC electric field. The corresponding discharge gap between the high-voltage electrodes and the grounded electrode was $100 \mathrm{~mm}$. The corresponding voltage was $28 \mathrm{kV}$. For each treatment, means with different lower case letters are significantly different $(p<0.05)$. (c) The evaporation loss, thawing loss, and drip loss of tofu under different electrode distances. The discharge gap was $8 \mathrm{~cm}, 9 \mathrm{~cm}, 10 \mathrm{~cm}, 11 \mathrm{~cm}$, and $12 \mathrm{~cm}$ with multiple needles-to-plate electrode for AC electric field, respectively. The corresponding voltage was $20 \mathrm{kV}$. For each treatment, means with different lower case letters are significantly different $(p<0.05)$.

temperatures of frozen tofu increased rapidly from $-10^{\circ} \mathrm{C}$ to $-2^{\circ} \mathrm{C}$. The center temperatures of frozen tofu also increased rapidly from $0^{\circ} \mathrm{C}$ to $10^{\circ} \mathrm{C}$ in the last $20 \mathrm{~min}$. With the increase of voltage, the increase rate of the center temperatures raised. As electrode distance increased, the increase rate of the center temperatures decreased. The center temperatures 
increased slowly between $-2^{\circ} \mathrm{C}$ and $0^{\circ} \mathrm{C}$ in all experimental conditions. Most of the thawing time is longer in the temperature range $\left(-2^{\circ} \mathrm{C}-0^{\circ} \mathrm{C}\right)$ than that of other temperature range. The center temperature range $\left(-5^{\circ} \mathrm{C}\right.$ to $\left.-1^{\circ} \mathrm{C}\right)$ is often taken as the zone of maximum ice crystal formation in the food freezing industry [14]. When the center temperature of frozen tofu is from $-2^{\circ} \mathrm{C}$ to $0^{\circ} \mathrm{C}$, high-voltage electric field treatment exerts its maximum effect. This result coincides with other studies [5]. There is a considerable variation about the thawing time exposed to $\mathrm{HVEF}$ at $-2^{\circ} \mathrm{C}-0^{\circ} \mathrm{C}$ when the voltages, the configuration of the electrodes and electrode distances changed. The thawing time under AC electric field is higher than that under DC electric field. There have different thawing time for the different configuration of the electrodes. The thawing time with needles-to-plate electrodes is faster than that with the other configuration of the electrodes. The thawing time with wires-to-plate electrodes is higher than that with plate-to-plate electrodes. Thus, the electric parameters have a major effect on the thawing time when center temperatures of frozen tofu are from $-2^{\circ} \mathrm{C}$ to $0^{\circ} \mathrm{C}$. As can be seen from Figure 3, the results indicate that the rising rate of center temperature increased with rise in voltage from $-2^{\circ} \mathrm{C}$ to $10^{\circ} \mathrm{C}$. When the corona wind blows to the surface of the material, the electrical conductivity of the frozen tofu would changes. Then, this would affect HVEF-assisted thawing process. The change of electrical conductivity of samples starts to apply HVEF. However, the effect on thawing is relatively small in the initial stage. The thawing effect increased with rise in the change of electrical conductivity of samples. When the electrical conductivity rises above a certain value, the thawing effect is more remarkable. And there is a great correlation between high voltage and the change of electrical conductivity of samples.

3.3. Evaporation Loss (EL), Thawing Loss (TL), and Drip Loss (DL) Analysis. Evaporation loss, thawing loss, and drip loss of the tofu samples were measured with different thawing parameters in our study. Effect of thawing parameters on the evaporation loss, thawing loss, and drip loss of tofu was given in Figure 4. Water holding capacity has a great relevance with thawing loss. Water holding capacity is high when thawing loss of the material samples is low [2]. The results showed that with the increase of voltages, evaporation loss increased. The evaporation rate of material samples treated with high-voltage electric field significantly accelerated compared to that of the control when the voltage is higher than a specific value [18-20]. Drip loss and thawing loss of frozen tofu were very close under DC electric field. Drip loss and thawing loss treated with high-voltage electric field were less than that with the control. The thawing loss under AC electric field is higher than that under DC electric field. Using the different configuration of the electrodes, the thawing rate is highest with needles-to-plate electrodes and is lower with plate-to-plate electrodes than that under the other experimental conditions. The evaporation loss decreased with increasing applied electrode distance. But drip loss and thawing loss increased with increasing applied electrode distance. As can be seen, the results indicate that changes in voltage make no great difference to thawing loss under DC electric field. The configuration of the electrodes and electrode distances has significant effects on thawing loss. In other words, water holding capacity of tofu is improved at certain experimental conditions using HVEF thawing. The thawing process can cause the structural changes of the tofu, and this change may lead to an increase in textural properties such as hardness, springiness, cohesiveness, and gumminess, which may match with consumer preferences for harder and springier tofu [21]. In the thawing process, the thawing time has a major effect on thawing loss. The thawing time of frozen tofu was significantly shortened under high-voltage electric field than that of the control.

\section{Conclusion}

Thawing under HVEF treatment significantly improved the thawing rate and shortened the thawing time of frozen tofu. As the voltage was enhanced, thawing rate increased. Voltage has a little effect on thawing loss under DC electric field. But the configuration of the electrodes and electrode distances has a major effect on thawing loss. In other words, the quality of thawed samples was improved by the HVEF thawing technology. We hope that this study can promote the industrial application of high-voltage electric field in the thawing field and attract more studies about HVEF thawing technique.

\section{Data Availability}

The data used to support the findings of this study are included within the article.

\section{Conflicts of Interest}

All authors declare that they have no conflicts of interest regarding the publication of this paper.

\section{Acknowledgments}

This work was supported by National Natural Science Foundations of China (nos. 51467015 and 51767020), College Students' Innovative and Entrepreneurial Training Program of Inner Mongolia (no. 201610128002), and Natural Science Foundation of Inner Mongolia Autonomous Region of China (no. 2017MS(LH)0507). The authors also would like to express their gratitude to the anonymous referees for their valuable comments and suggestions.

\section{References}

[1] X. He, G. Jia, E. Tatsumi, and H. Liu, "Effect of corona wind, current, electric field and energy consumption on the reduction of the thawing time during the high-voltage electrostatic-field (HVEF) treatment process," Innovative Food Science and Emerging Technologies, vol. 34, pp. 135-140, 2016.

[2] X. He, R. Liu, S. Nirasawa, D. Zheng, and H. Liu, "Effect of high voltage electrostatic field treatment on thawing 
characteristics and post-thawing quality of frozen pork tenderloin meat," Journal of Food Engineering, vol. 115, no. 2, pp. 245-250, 2013.

[3] X. He, R. Liu, E. Tatsumi, S. Nirasawa, and H. Liu, "Factors affecting the thawing characteristics and energy consumption of frozen pork tenderloin meat using high-voltage electrostatic field," Innovative Food Science and Emerging Technologies, vol. 22, pp. 110-115, 2014.

[4] A. Mousakhani-Ganjeh, N. Hamdami, and N. Soltanizadeh, "Impact of high voltage electric field thawing on the quality of frozen tuna fish (Thunnus albacares)," Journal of Food Engineering, vol. 156, pp. 39-44, 2015.

[5] A. Mousakhani-Ganjeh, N. Hamdami, and N. Soltanizadeh, "Thawing of frozen tuna fish (Thunnus albacares) using still air method combined with a high voltage electrostatic field," Journal of Food Engineering, vol. 169, pp. 149-154, 2016.

[6] A. Mousakhani-Ganjeh, N. Hamdami, and N. Soltanizadeh, "Effect of high voltage electrostatic field thawing on the lipid oxidation of frozen tuna fish (Thunnus albacares)," Innovative Food Science and Emerging Technologies, vol. 36, pp. 42-47, 2016.

[7] G. L. Jia, S. Nirasawa, X. H. Ji, Y. K. Luo, and H. J. Liu, "Physicochemical changes in myofibrillar proteins extracted from pork tenderloin thawed by a high-voltage electrostatic field," Food Chemistry, vol. 240, pp. 910-916, 2018.

[8] M. Rahbari, N. Hamdami, H. Mirzaei, S. M. Jafari, M. Kashaninejad, and M. Khomeiri, "Effects of high voltage electric field thawing on the characteristics of chicken breast protein," Journal of Food Engineering, vol. 216, pp. 98-106, 2018.

[9] G. L. Jia, H. J. Liu, S. Nirasawa, and H. J. Liu, "Effects of highvoltage electrostatic field treatment on the thawing rate and post-thawing quality of frozen rabbit meat," Innovative Food Science and Emerging Technologies, vol. 41, pp. 348-356, 2017.

[10] Y. Bai, Y. Huo, and X. Fan, "Experiment of thawing shrimps (Penaeus vannamei) with high voltage electric field," International Journal of Applied Electromagnetics and $\mathrm{Me}$ chanics, vol. 55, pp. 499-506, 2017.

[11] D. P. Li, S. L. Jia, L. T. Zhang et al., "Post-thawing quality changes of common carp (Cyprinus carpio) cubes treated by high voltage electrostatic field (HVEF) during chilled storage," Innovative Food Science and Emerging Technologies, vol. 42, pp. 25-32, 2017.

[12] S. Deng, Z. Gao, J. Xu, G. Wang, Y. Bai, and C. Ding, "The thawing characteristic of frozen tofu under high-voltage alternating electric field," Journal of Food Quality, vol. 2017, Article ID 3914074, 6 pages, 2017.

[13] O. Parniakov, O. Bals, N. Lebovka, and E. Vorobiev, "Effects of pulsed electric fields assisted osmotic dehydration on freezing-thawing and texture of apple tissue," Journal of Food Engineering, vol. 183, pp. 32-38, 2016.

[14] C. W. Hsieh, C. H. Lai, W. J. Ho, S. C. Huang, and W. C. Ko, "Effect of thawing and cold storage on frozen chicken thigh meat quality by high-voltage electrostatic field," Journal of food science, vol. 75, no. 4, pp. M193-M197, 2010.

[15] C. Ding, J. Lu, and Z. Song, "Electrohydrodynamic drying of carrot slices," PLoS One, vol. 10, Article ID e0124077, 2015.

[16] C. J. Backi, "Methods for (industrial) thawing of fish blocks: a review," Journal of Food Process Engineering, vol. 41, article e12598, 2018.

[17] S. V. Shevkunov and A. Vegiri, "Electric field induced transitions in water clusters," Journal of Molecular Structure: THEOCHEM, vol. 593, no. 1-3, pp. 19-32, 2002.
[18] C. Ding, J. Lu, Z. Song, and S. Bao, "The drying efficiency of electrohydrodynamic (EHD) systems based on the drying characteristics of cooked beef and mathematical modeling," International Journal of Applied Electromagnetics and Mechanics, vol. 46, pp. 455-461, 2014.

[19] A. Singh, V. Orsat, and V. Raghavan, "A comprehensive review on electrohydrodynamic drying and high-voltage electric field in the context of food and bioprocessing," Drying Technology, vol. 30, no. 16, pp. 1812-1820, 2012.

[20] S. Isobe, N. Barthakur, T. Yoshino, L. Okushima, and S. Sase, "Electrohydrodynamic drying characteristics of agar gel," Food Science and Technology Research, vol. 5, no. 2, pp. 132-136, 1999.

[21] Y. Xu, Y. Tao, and S. Shivkumar, "Effect of freeze-thaw treatment on the structure and texture of soft and firm tofu," Journal of Food Engineering, vol. 190, pp. 116-122, 2016. 


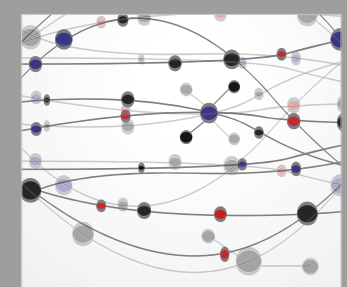

The Scientific World Journal
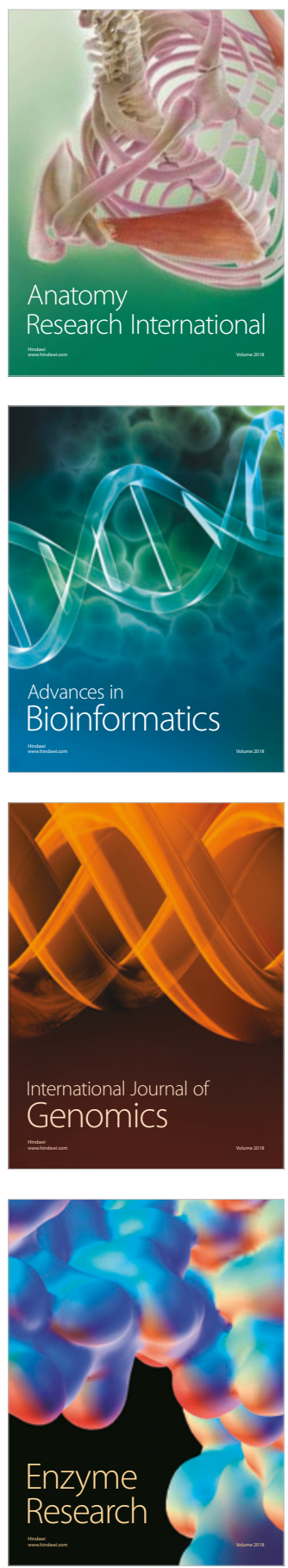
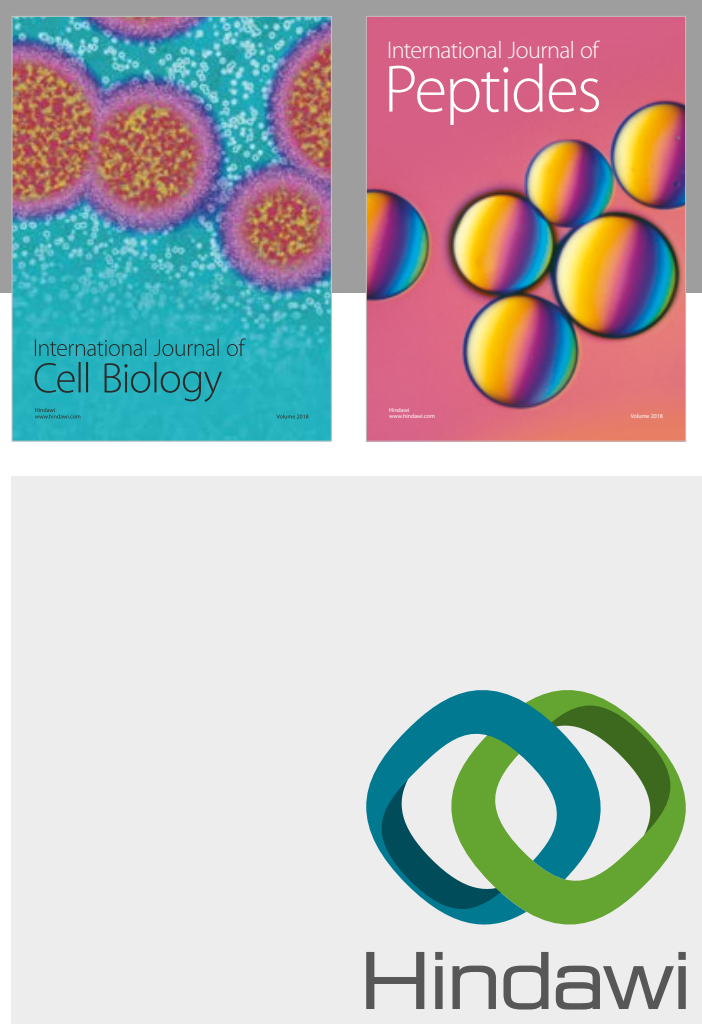

Submit your manuscripts at

www.hindawi.com
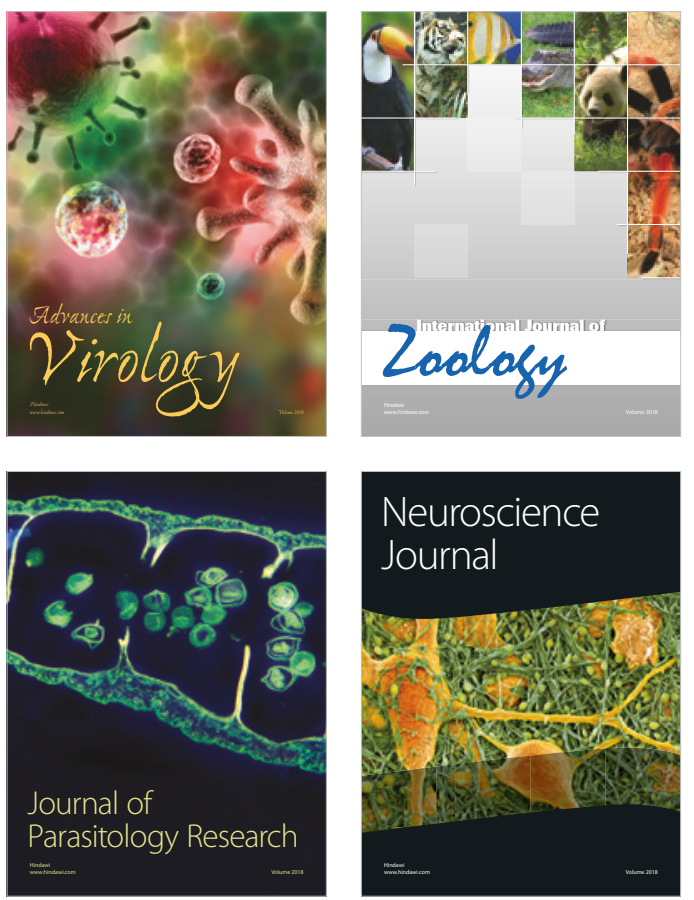
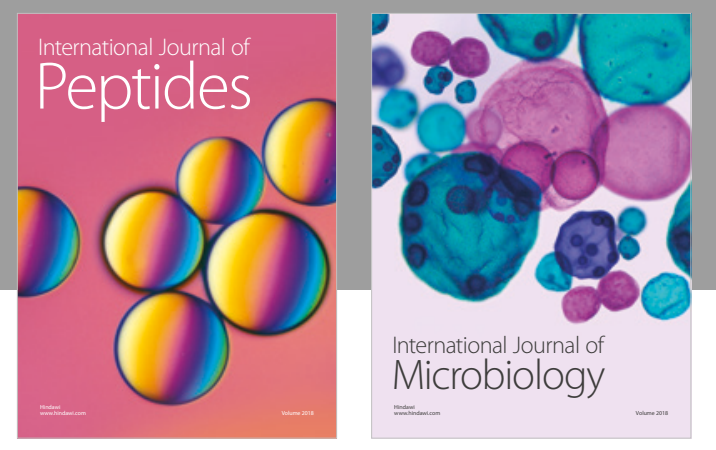

nternational Journal of Microbiology
Journal of
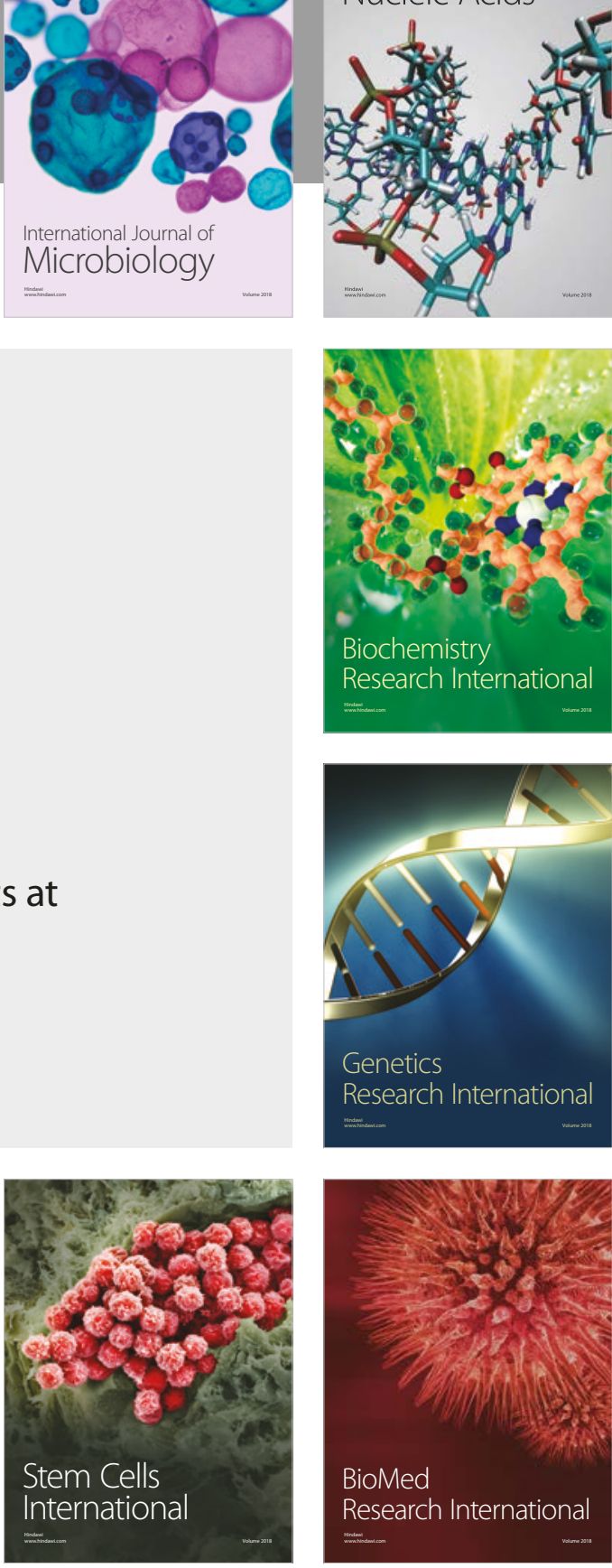
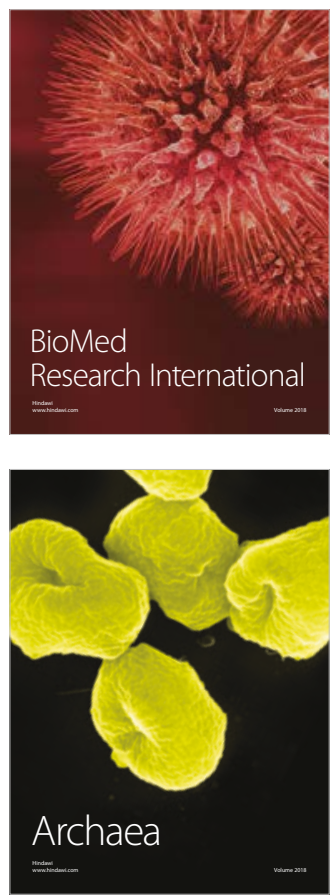